Review began 09/27/2021 Review ended 10/01/2021 Published 10/07/2021 Exp. concern 04/07/2022

\section{(c) Copyright 2021}

Aldabbab et al. This is an open access article distributed under the terms of the Creative Commons Attribution License CCBY 4.0., which permits unrestricted use, distribution, and reproduction in any medium, provided the original author and source are credited.

\title{
Isolated Polycystic Liver Disease: A Rare Genetic Disorder
}

Habib Y. Aldabbab ${ }^{1}$, Moayad A. Hakeem ${ }^{2}$, Fatimah M. Alanazi ${ }^{3}$, Mohammed A. Asiri ${ }^{4}$, Mohammad F. Al Hani $^{5}$, Rahaf I. Alshareef ${ }^{6}$, Abeer R. Alkahtani ${ }^{6}$, Rahaf F. Alfadhli ${ }^{6}$, Lama Y. Alharbi ${ }^{6}$, Abdulla A. Jan ${ }^{6}$, Mohanned M. Alraddadi ${ }^{7}$, Malak Alshammari ${ }^{8}$

1. College of Medicine, King Faisal University, Al-Ahsa, SAU 2. College of Medicine, University of Jeddah, Jeddah, SAU 3. College of Medicine, Northern Border University, Arar, SAU 4. College of Medicine, King Saud University, Riyadh, SAU 5. Internal Medicine, Ras Tanura General Hospital, Ras Tanura, SAU 6. College of Medicine, Imam Mohammad Ibn Saud Islamic University, Riyadh, SAU 7. College of Medicine, Majmaah University, Al Majma'ah, SAU 8. College of Medicine, Imam Abdulrahman Bin Faisal University, Dammam, SAU

Corresponding author: Malak Alshammari, saudidoctor2020@gmail.com

\section{Expression of Concern}

Expression of Concern date: April 07, 2022. Cite this expression of concern as Aldabbab H Y, Hakeem M A, Alanazi F M, et al. (April 07, 2022) Expression of Concern: Isolated Polycystic Liver Disease: A Rare Genetic Disorder. Cureus 14(4): x6. doi:10.7759/cureus.x6.

The concern relates to the provenance of this article as brought to our attention by Faisal Alhawaj, who denies authorship of this article and others published in Cureus. These articles were submitted and subsequently published purportedly as an effort coordinated by Imam Abdulrahman Bin Faisal University to ensure all medical interns publish at least one peer-reviewed article in order to qualify for enrollment in a postgraduate residency program as stipulated by The Saudi Commission for Health Specialties (SCFHS).

The journal has not been presented with enough evidence to warrant the formal retraction of these articles as both Imam Abdulrahman Bin Faisal University and The Saudi Commission for Health Specialties have failed to respond to numerous communications requesting additional information regarding these allegations. While we acknowledge that the provenance of these articles is very much in question, we cannot act until these claims have been investigated by the appropriate institutions with the results of said investigation communicated to Cureus.

The concern and this note will remain appended to the above-mentioned article until Cureus is provided with official confirmation from Imam Abdulrahman Bin Faisal University or The Saudi Commission for Health Specialties.

\section{Abstract}

Polycystic liver disease is a rare clinical condition that causes portal hypertension. It constitutes a group of disorders with liver lesions resulting from abnormal development of the embryological ductal system. Isolated polycystic disease with the absence of polycystic kidney disease is considered a rare condition. We present the case of a 46-year-old man who presented with epigastric pain and episodes of hematemesis. Abdominal examination revealed enlarged liver. He underwent a computed tomography scan that revealed innumerable cystic liver lesions with the presence of ascites. Further investigations confirmed abnormal liver functions and portal hypertension. Physicians need to consider this diagnosis in the appropriate clinical settings. Extensive involvement of the liver may lead to persistent severe symptoms requiring liver transplantation.

Categories: Radiology, Gastroenterology, General Surgery

Keywords: case report, genetic disorder, hematemesis, abdominal pain, polycystic liver disease

\section{Introduction}

Epigastric abdominal pain is a common complaint in the emergency department. It typically includes common cardiac, hepatic, biliary, and pancreatic etiologies. However, polycystic liver disease is a rare clinical condition that causes portal hypertension. It constitutes a group of disorders with liver lesions resulting from abnormal development of the embryological ductal system. Polycystic liver disease is usually due to autosomal dominant conditions in adults [1]. However, isolated polycystic disease is rare. Herein, we presented the case of a middle-aged man who presented with epigastric pain and episodes of hematemesis that were eventually diagnosed as isolated polycystic liver disease.

\section{Case Presentation}




\section{Cureus}

A 46-year-old man presented to the emergency department with abdominal pain for a one-week duration. He reported that the pain was gradually increasing in intensity. The pain was diffuse but mainly located in the epigastrium. It was constant pain and associated with decreased appetite, abdominal distension, and recurrent episodes of vomiting that contains blood. He did not report a report any change in bowel or urinary habits. His past surgical history included a laparoscopic appendectomy; otherwise, he was healthy and did not experience any health issues. He does not drink alcohol or smoke cigarettes. There was no history of liver diseases in the family.

On examination, the patient was alert, conscious, and oriented. The general examination appeared normal. His vital signs were as follows: temperature of $37.2^{\circ} \mathrm{C}$, heart rate of $120 \mathrm{bpm}$, respiratory rate of $18 \mathrm{bpm}$, and blood pressure of 112/70 mmHg. Abdominal examination revealed a distended abdomen with an enlarged liver span. Further, he was noted to have moderate ascites. Cardiorespiratory examination revealed normal findings. Laboratory findings revealed a mild elevation in the liver enzymes with an aspartate transaminase level of $51 \mathrm{U} / \mathrm{L}$ and an alanine transaminase level of $67 \mathrm{U} / \mathrm{L}$. The albumin level was $2.9 \mathrm{~g} / \mathrm{dL}$ and the bilirubin level was $1.3 \mathrm{~g} / \mathrm{dL}$. The blood glucose level was within the normal limits. Hematological and other biochemical investigations revealed normal findings (Table 1).

\begin{tabular}{|c|c|c|c|}
\hline Laboratory Investigation & Unit & Result & Reference Range \\
\hline Hemoglobin & g/dL & 13.1 & 13.0-18.0 \\
\hline White Blood Cell & 1000/mL & 8.2 & $4.0-11.0$ \\
\hline Platelet & 1000/mL & 340 & $140-450$ \\
\hline Erythrocyte Sedimentation Rate & $\mathrm{mm} / \mathrm{hr}$. & 19 & $0-20$ \\
\hline C-Reactive Protein & $\mathrm{mg} / \mathrm{dL}$ & 8.3 & $0.3-10.0$ \\
\hline Total Bilirubin & $\mathrm{mg} / \mathrm{dL}$ & 1.3 & $0.2-1.2$ \\
\hline Albumin & g/dL & 2.9 & $3.4-5.0$ \\
\hline Alkaline Phosphatase & $\mathrm{U} / \mathrm{L}$ & 50 & $46-116$ \\
\hline Gamma-Glutamyltransferase & $\mathrm{U} / \mathrm{L}$ & 45 & 15-85 \\
\hline Alanine Transferase & U/L & 67 & $14-63$ \\
\hline Aspartate Transferase & $\mathrm{U} / \mathrm{L}$ & 51 & 15-37 \\
\hline Lactate Dehydrogenase & $\mathrm{U} / \mathrm{L}$ & 150 & 140-280 \\
\hline Blood Urea Nitrogen & $\mathrm{mg} / \mathrm{dL}$ & 17 & $7-18$ \\
\hline Creatinine & $\mathrm{mg} / \mathrm{dL}$ & 1.1 & $0.7-1.3$ \\
\hline Sodium & $\mathrm{mEq} / \mathrm{L}$ & 136 & $136-145$ \\
\hline Potassium & $\mathrm{mEq} / \mathrm{L}$ & 3.6 & $3.5-5.1$ \\
\hline Chloride & $\mathrm{mEq} / \mathrm{L}$ & 105 & 98-107 \\
\hline D-Dimer & $\mathrm{ng} / \mathrm{mL}$ & 400 & $220-500$ \\
\hline Prothrombin Time & $\sec$ & 13.0 & 11-13.5 \\
\hline Partial Thromboplastin Time & sec & 30 & $25-35$ \\
\hline
\end{tabular}

TABLE 1: Summary of the results of laboratory findings

The patient underwent abdominal ultrasound examination, which showed an enlarged liver with diffuse multiple cysts. The patient was resuscitated with intravenous fluid hydration. Subsequently, he underwent a computed tomography scan of the abdomen, which revealed innumerable, homogeneous, and hypoattenuating cystic lesions in the liver (Figure 1). The portal vein measures $23 \mathrm{~mm}$ in diameter. Both kidneys were normal. Given the extensive cystic disease, the patient was referred to a hepatology center for possible liver transplantation. 


\section{Cureus}

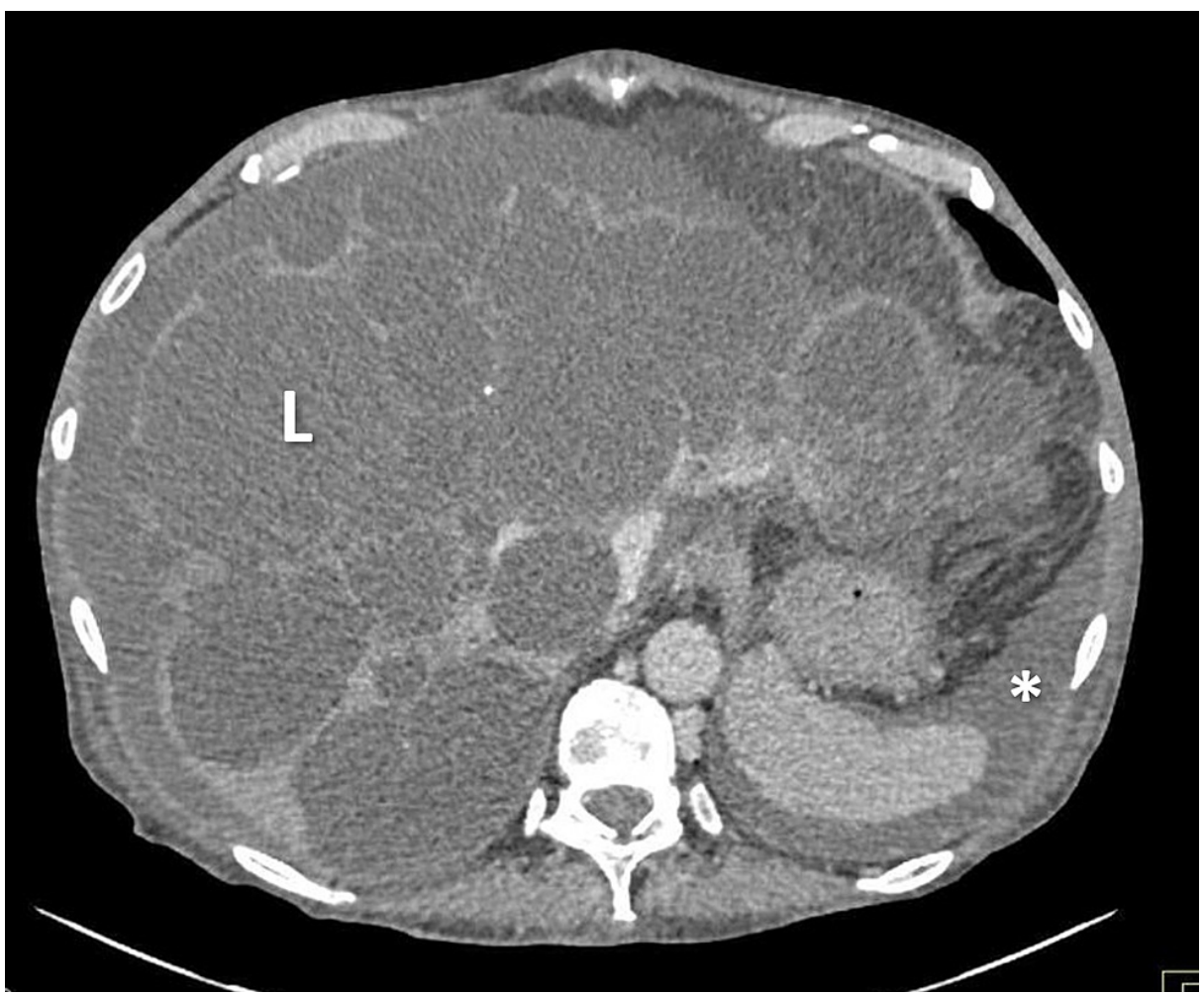

\section{FIGURE 1: Computed tomography}

Computed tomography image showing innumerable, homogeneous, and hypoattenuating cystic lesions in the liver (L) along with ascites (asterisk)

\section{Discussion}

We presented the case of a middle-aged man with isolated polycystic liver disease presenting with abdominal pain and hematemesis. In this condition, the hepatic involvement ranges from limited areas of cystic disease to diffuse hepatic involvement of all segments of the liver. It is an autosomal dominant condition resulting in malformation of the ductal plate of the small intrahepatic ducts. However, there was no family history of liver disease in the family indicating a sporadic form of polycystic liver disease. It is reported that up to $50 \%$ of cases are related to mutations in the PRKCSH or SEC63 genes [2].

Several anomalies have been described in patients with polycystic liver disease. These anomalies include biliary hamartoma, Caroli disease, and polycystic kidney disease [3]. In the present case, however, the patient did not have any other association. The typical presentation of polycystic liver disease includes a non-specific, dull abdominal pain, abdominal dimension, shortness of breath, and early satiety. Such symptoms were present in our case. Additionally, the polycystic liver can exert extrinsic compression of the portal vein resulting in portal hypertension. Polycystic liver disease is more prevalent among women. Further, pregnancy and exogenous estrogen use are considered risk factors for this disorder. Hence, some hypotheses suggest a possible hormonal role in the pathogenesis of liver cysts.

The management options for polycystic liver disease include medical and surgical approaches. The medical approaches include the use of somatostatin analogs to decrease the size of the hepatic cysts [4]. Additionally, percutaneous aspiration of the cysts may be used. Total hepatectomy or liver transplantation may be considered in severe cases [5]. Generally, patients with polycystic liver disease have a good prognosis and do not exhibit the typical liver cirrhosis pathway. The indication of liver transplantation for these patients is generally related to the severity of symptoms and their impact on the quality of life of patients.

The presence of liver cysts along with elevated glucose levels should raise the suspicion of the maturityonset diabetes of the young (MODY). In type 5, there is a mutation in the HFN1B gene, which plays a key role in the development of multiple organs, including the kidneys, liver, and pancreas. Patients with MODY5 may have pancreatic dysfunction, liver disease, and renal cysts [6].

\section{Conclusions}

Isolated polycystic liver disease is a rare clinical entity. Physicians need to consider this diagnosis in patients with abdominal pain, ascites, and enlarged liver, even in the absence of a family history of liver 


\section{Additional Information}

\section{Disclosures}

Human subjects: Consent was obtained or waived by all participants in this study. Conflicts of interest: In compliance with the ICMJE uniform disclosure form, all authors declare the following: Payment/services info: All authors have declared that no financial support was received from any organization for the submitted work. Financial relationships: All authors have declared that they have no financial relationships at present or within the previous three years with any organizations that might have an interest in the submitted work. Other relationships: All authors have declared that there are no other relationships or activities that could appear to have influenced the submitted work.

\section{References}

1. Khan MS, Khan Z, Javaid T, et al.: Isolated polycystic liver disease: an unusual cause of recurrent variceal bleed. Case Rep Gastrointest Med. 2018, 2018:2902709. 10.1155/2018/2902709

2. van Aerts RM, van de Laarschot LF, Banales JM, Drenth JP: Clinical management of polycystic liver disease . J Hepatol. 2018, 68:827-37. 10.1016/j.jhep.2017.11.024

3. Cnossen WR, Drenth JP: Polycystic liver disease: an overview of pathogenesis, clinical manifestations and management. Orphanet J Rare Dis. 2014, 9:69. 10.1186/1750-1172-9-69

4. Gevers TJ, Drenth JP: Somatostatin analogues for treatment of polycystic liver disease. Curr Opin Gastroenterol. 2011, 27:294-300. 10.1097/MOG.0b013e328343433f

5. Morgan DE, Lockhart ME, Canon CL, Holcombe MP, Bynon JS: Polycystic liver disease: multimodality imaging for complications and transplant evaluation. Radiographics. 2006, 26:1655-68; quiz 1655. 10.1148/rg.266065013

6. Mateus JC, Rivera C, O'Meara M, Valenzuela A, Lizcano F: Maturity-onset diabetes of the young type 5 a MULTISYSTEMIC disease: a CASE report of a novel mutation in the HNF1B gene and literature review. Clin Diabetes Endocrinol. 2020, 6:16. 10.1186/s40842-020-00103-6 